\title{
Layered double hydroxide functionalized biomass carbon fiber for highly efficient and recyclable fluoride adsorption
}

\author{
Tao Zhang ${ }^{1 *}\left(\mathbb{D}\right.$, Bencheng Zhao ${ }^{1}$, Qiuyun Chen ${ }^{1}$, Xiaoming Peng ${ }^{2}$, Dongya Yang ${ }^{1}$ and Fengxian Qiu ${ }^{1}$
}

\begin{abstract}
The removing of fluoride from water is highly desired from the viewpoint of environmental protection and sustainable development due to the adverse impacts on human and ecosystem. In this study, the hierarchical porous layered double hydroxide (LDH)/biomass carbon fiber (BCF) has been successfully fabricated by the combined sol-gel, carbonization and hydrothermal processes using sustainable bamboo fibers as raw material based on the assembly the LDH nanosheets on BCF surfaces. Structural characterization indicates that the LDH nanosheets were attached to the BCF surface via in situ crystal growth. $\mathrm{N}_{2}$ sorption measurements show that the LDH/BCF has relatively uniform accessible mesochannel size of $3.56 \mathrm{~nm}$, and the surface area is as high as $39.89 \mathrm{~m}^{2} / \mathrm{g}$. The resulting LDH/BCF exhibit a noticeable enhanced adsorption capacity for fluoride removal compared to that of $\mathrm{Al}_{2} \mathrm{O}_{3} / \mathrm{BCF}$, accompanied by $15.21 \mathrm{mg} / \mathrm{g}$ of the adsorption capacity. The presence of the high negative charge anions had negligible influence on fluoride adsorption. Importantly, recovery adsorption capacity for fluoride was obtained for LDH/BCF for 5 consecutive cycles without a significant decrease in its adsorption properties. Therefore, the current research can offer a green approach to fabricate $\mathrm{LDH} / \mathrm{BCF}$ with hierarchical structures for efficient removing fluoride from water, and the fabricated LDH/BCF will be an excellent candidate for pollution control based on the synergistic effects of BCF and LDH, high adsorption properties with good reusability.
\end{abstract}

Keywords: Adsorption, Biomass, Fluoride, Layered double hydroxide, Reusability

\section{Introduction}

Groundwater and surfacewater, which are the main source of domestic and agricultural water in underdeveloped countries, their contaminations by fluoride ions have raised great concerns because the excess fluoride ions can cause potential risk to human and animal health by drinking water or food chain [1]. Long-term drinking of high-fluorine water can result in dental fluorosis, skeletal fluorosis [2], as well as the lesions of tissues and organs (such as the endocrine glands, thyroid and liver) [3]. Fluoride contamination in the groundwater occurs in any parts of world, particularly in Bangladesh, Thailand,

\footnotetext{
*Correspondence: zhangtaochem@163.com

${ }^{1}$ Institute of Green Chemistry and Chemical Technology, School of Chemistry and Chemical Engineering, Jiangsu University,

Zhenjiang 212013, China

Full list of author information is available at the end of the article
}

Pakistan, China, India, Africa, and Mexico [4]. Elevated fluoride concentrations in the groundwater derives mainly from natural dissolution of minerals from rocks and soils [5]. In addition, excess fluoride in surface water is prevalent in wastewaters derived from glass industry, metallurgy, phosphorus ore processing, electroplating and high-tech industries such as photovoltaics, semiconductor industry and electronic ceramics [6]. Therefore, the fluoride contaminated water has to be treated before it is discharge.

It is well recognized that the quality of agricultural water is very important for food safety and quality of life. Toxic cations, such as heavy metal ions, have been a serious ecological problem due to bioaccumulation through the food chain, while anions, such as $\mathrm{SO}_{4}{ }^{2-}$, $\mathrm{Cl}^{-}$and $\mathrm{CO}_{3}{ }^{2-}$, can cause soil consolidation or decrease soil fertility [7]. It is common that the groundwater (or surface water) can be used directly without purification 
for agricultural irrigation. The poisonous agricultural water containing heavy metal ions has induced more and more public concerns, and numerous investigations have focused on the removal of heavy metal ions from agricultural water. However, little is known about how anionic contaminants can influence the agricultural crops and in turn alter the agricultural products. There are some reports indicating that fluoride can inhibit enzyme activity of plants that involved in DNA transcription and replication processes $[8,9]$. In addition, fluoride can also interfere with proteins and disrupt the metabolism, pespiration and photosynthesis of plants [10]. Recent reports demonstrated that fluoride ions in agricultural water can enhance the solubility of metal oxide, causing the bioaccumulation of harmful ions and inhibition of phosphorus absorption [8]. Therefore, efficient treatment of fluoridecontaining wastewater is essential for food safety, following the rapid development of agricultural engineering.

To date, a variety of methods such as adsorption [11], chemical precipitation [12], electrodialysis [13] and membrane processes [14] have been used to remove or separate fluoride from water. Despite this, effective technologies are sought because, although some of these defluoridation methods are very effective in removing fluoride from water (e.g., electrodialysis or membrane processes), they have several drawbacks, i.e., high operational and maintenance costs, the production of residual toxic by-products and complicated procedures. Recently, functional nano adsorbents are drawn the significant attention based on the extreme selectivity to the fluoride and high adsorption properties due to the basic simplicity of the adsorption process. In particular, some interesting properties of nano-adsorbents such as their high adsorption capacity, high BET specific surface area, porous structure and surface functionalization make them highly suitable materials for gas adsorption. Moreover, the nano-adsorbents have exhibited no internal diffusion resistance during the adsorption, which makes the fluoride adsorption more effective. However, the high surface energy of nano-adsorbents makes them extremely reactive, and most systems undergo aggregation. Moreover, nanosized nano-adsorbents are difficult to recycle from the reaction media, which may cause secondary pollution of water. Therefore, key point for fluoride adsorption is the possibility to regenerate the adsorbent and to recycle it for repeated use.

For water treatment, a reliable adsorbent for defluorination must exhibit not only rapid adsorption kinetics, but also high fluoride adsorption efficiency and selectivity. Therefore, seeking a simple method for cost-effective and large-scale preparation of fluoride adsorbents with high adsorption capacity remains a severe challenge. Biomass carbon $(\mathrm{BC})$ is a stable carbon dominant material with a highly porous structure which is produced by thermal stabilization of biomass under oxygen depleted conditions $[15,16]$. The application of $\mathrm{BC}$ materials is considered a promising, cost-effective, eco-friendly alternative materiaapproach for fluoride adsorption due to their renewable, abundant functional groups and porous structure features. The adsorption sites of adsorbents used in fluoride adsorption significantly affects the adsorption process (equilibrium state and adsorption kinetic), since the adsorption capacity and adsorption strength are controlled by surface sites. However, the BC materials have low fluoride adsorption properties due to the limited surface sites. To obtain high surface activity (high porosity and high surface area) and excellent fluoride adsorption efficiency, it is of interest to develop the $\mathrm{BC}$ composites that combine the advantages of $\mathrm{BC}$ materials and the functional properties of nano-adsorbents.

The purpose of this study is to fabricate $\mathrm{LDH} / \mathrm{BCF}$ composites by using the biomass as a precursor of $\mathrm{BC}$, and its application for fluoride removal. The BCF materials with fiber structures are prepared by carbonization of bamboo fiber. Then, LDH/BCF composites are prepared simply by in situ growth of LDH nanosheets on the surface of $\mathrm{BC}$ materials. Batch adsorption experiments were conducted to investigate the fluoride removal properties. These results indicate that the LDH/BCF have potential as a green cost-effective adsorbent for treatment of fluoride-containing wastewater.

\section{Materials and methods Preparation of $\mathrm{LDH} / \mathrm{BCF}$}

The LDH/BCF was prepared based on the sol-gel and carbonization processes described by our previous study with some modifications [17, 18]. Typically, $0.5 \mathrm{~g}$ of treated cellulose was immersed into the $200 \mathrm{~mL}$ of alumina sol under ultrasound for $10 \mathrm{~min}$. After that, cellulose was washed with deionized water several times to remove non-adsorbed metal ions. After being dried at $100{ }^{\circ} \mathrm{C}$ for $12 \mathrm{~h}$, the aluminum coated biomass cellulose was calcined at $600{ }^{\circ} \mathrm{C}$ for $4 \mathrm{~h}$ under flowing nitrogen to obtain $\mathrm{Al}_{2} \mathrm{O}_{3} / \mathrm{BCF}$.

The preparation of $\mathrm{LDH} / \mathrm{BCF}$ was prepared by the hydrothermal method that involves in situ growth of $\mathrm{LDH}$ nanosheets on the fiber surface. Briefly, the above $\mathrm{Al}_{2} \mathrm{O}_{3} / \mathrm{BCF}$ was added into the $100 \mathrm{~mL}$ of alumina sol under ultrasound for $10 \mathrm{~min}$, followed by drying at $160{ }^{\circ} \mathrm{C}$ for $12 \mathrm{~h}$. The dried samples were immersed in $60 \mathrm{~mL}$ the mixed solution containing $\mathrm{Mg}\left(\mathrm{NO}_{3}\right)_{2}(0.513 \mathrm{~g})$ and HMT $(0.56 \mathrm{~g})$. Then the mixtures were transferred to a $100 \mathrm{~mL}$ of Teflon-lined autoclave for hydrothermal treatment at $120{ }^{\circ} \mathrm{C}$ for $16 \mathrm{~h}$. After that, the LDH/BCF was collected, washed with deionized water, and dried at $100{ }^{\circ} \mathrm{C}$ for $12 \mathrm{~h}$. Finally, the obtained LDH/BCF products 
were calcined under nitrogen at $500{ }^{\circ} \mathrm{C}$ for $4 \mathrm{~h}$ to obtain fluoride adsorbent.

\section{Fluoride adsorption}

The fluoride adsorption was performed by batch adsorption experiments and was conducted by mixing $0.1 \mathrm{~g}$ of $\mathrm{LDH} / \mathrm{BCF}$ with $50 \mathrm{~mL}$ of fluoride solution at different initial concentrations. The effects of the adsorption factors, such as $\mathrm{pH}$, interfering ions, adsorption times and temperatures, were investigated by variation of experimental conditions. The equilibrium isotherms were investigated by varying the fluoride concentrations and adsorption temperatures, while the adsorption kinetics were investigated by varying the adsorption times and temperatures. After adsorption, the fluoride concentrations in the solution were analyzed with a fluoride ion selective electrode (PF-1), then the amount of adsorbed fluoride was calculated from following equation:

$$
q_{t}=\frac{\left(C_{0}-C_{t}\right) V}{m}
$$

where $q_{t}$ is the fluoride adsorption capacity $(\mathrm{mg} / \mathrm{g})$ at time $t, C_{0}$ and $C_{t}$ are the fluoride concentrations, $V$ is the volume $(\mathrm{mL})$ of fluoride solution and $\mathrm{m}$ is the mass $(\mathrm{g})$ of adsorbents dose.

\section{Results and discussion}

The $\mathrm{LDH} / \mathrm{BCF}$ is obtained by using the combined method that involves carbonization and in situ growth method. Firstly, the $\mathrm{Al}_{2} \mathrm{O}_{3} / \mathrm{BCF}$ was prepared through the thermal decomposition of aluminum sol coated biomass. Then, LDH nanosheets were formed at the crystal growth stage under hydrothermal conditions. Additional file 1: Fig. $\mathrm{S} 1$ displays the representative SEM images of $\mathrm{Al}_{2} \mathrm{O}_{3} /$ $\mathrm{BCF}$ and $\mathrm{LDH} / \mathrm{BCF}$ with different magnifications. As shown in Additional file 1: Fig. $\mathrm{S} 1(\mathrm{~A})$ and (B), the $\mathrm{Al}_{2} \mathrm{O}_{3}$ / $\mathrm{BCF}$ exhibits fiber structures with fairly smooth surface and the diameter of $\mathrm{Al}_{2} \mathrm{O}_{3} / \mathrm{BCF}$ mainly ranged from 20 to $25 \mu \mathrm{m}$. In addition, the trenches were found on the surfaces of $\mathrm{Al}_{2} \mathrm{O}_{3} / \mathrm{BCF}$ along the fiber axial. It has been demonstrated that the in situ growth technology is able to fabricate hierarchically structured LDH with high surface activity on the surface of carbon material, alumina fiber, glass substrate [19, 20]. Additional file 1: Fig. 1S (C) and (D) show a typical SEM image of LDH/BCF. Compared with the $\mathrm{Al}_{2} \mathrm{O}_{3} / \mathrm{BCF}$, a layer of $\mathrm{LDH}$ nanosheets were observed on the surfaces of $\mathrm{BCF}$ which endowed the high BET specific surface area of $\mathrm{LDH} / \mathrm{BCF}$, indicating that the $\mathrm{LDH}$ nanosheets were attached to the $\mathrm{BCF}$ surface by carbonization of biomass followed by in situ growth. The LDH nanocrystals with sheet-like structure of 0.5-1.5 $\mu \mathrm{m}$ and good dispersion were formed on BCF surface. The exposed LDH nanosheets also present the possibility for further binding with fluoride ion for pollution treatment.

To determine the crystal structure of the biomass materials, XRD measurement was conducted and the XRD patterns are presented in Fig. 1. The XRD pattern of $\mathrm{Al}_{2} \mathrm{O}_{3} / \mathrm{BCF}$ displays a broad and low diffraction peak at $2 \theta=23.5^{\circ}$, which is corresponding to the (002) plane of biomass carbon. However, as illustrated in Fig. 2, there is no characteristic peak of $\mathrm{Al}_{2} \mathrm{O}_{3}$ and only $\mathrm{BCF}$ characteristic diffraction remained due to the amorphous nature of $\mathrm{Al}_{2} \mathrm{O}_{3}$. After decorated by LDH nanosheets, the characteristic diffraction peaks appear at $11.64^{\circ}, 23.42^{\circ}$, $34.88^{\circ}, 39.38^{\circ}$ and $47.00^{\circ}$, which correspond to the (003), (006), (012), (015), and (018) planes of LDH. Simultaneously, the diffraction peak of BCF is observed. In this case, the introduction of functional LDH nanosheets on the surfaces of BCF can increase the fluoride adsorption capacity of $\mathrm{LDH} / \mathrm{BCF}$ due to the combination of the advantages of both LDH nanosheets and BCF.

The solution $\mathrm{pH}$ controls the surfaces charge density of $\mathrm{LDH} / \mathrm{BCF}$ and influence the degree of fluoride adsorption. Figure 2a shows the influence of $\mathrm{pH}$ on the fluoride adsorption capacities of $\mathrm{LDH} / \mathrm{BCF}$. As can be seen from the Fig. 2a, the solution $\mathrm{pH}$ of the solution is crucial for fluoride adsorption and the optimum $\mathrm{pH}$ for fluoride adsorption appeared at $\mathrm{pH} 3.5-9.0$. At the low $\mathrm{pH}$ region, the layer structures of LDH may damage at acidic environments and thus reduces the fluoride adsorption capacities. At the high $\mathrm{pH}$ region, the surfaces of $\mathrm{LDH} /$ BCF were exposed and carried positive charges, which results in the electrostatic repulsions between fluoride ions and adsorbents. The fluoride adsorption was low due to the presence of $\mathrm{OH}^{-}$ions competing with the fluoride ions for the adsorption sites of the LDH/BCF. The maximum fluoride adsorption capacity of LDH/BCF

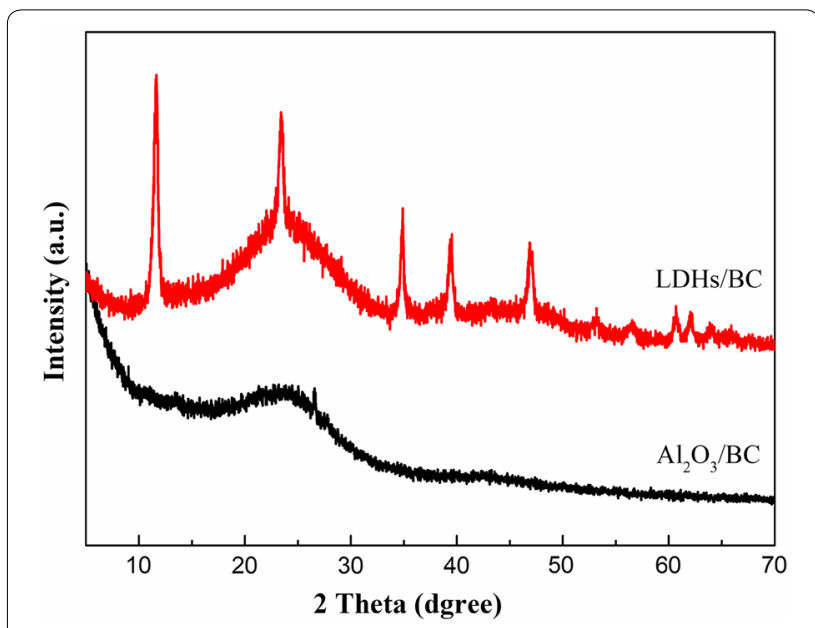

Fig. 1 XRD patterns of $\mathrm{Al}_{2} \mathrm{O}_{3} / \mathrm{BCF}$ and $\mathrm{LDH} / \mathrm{BCF}$ 

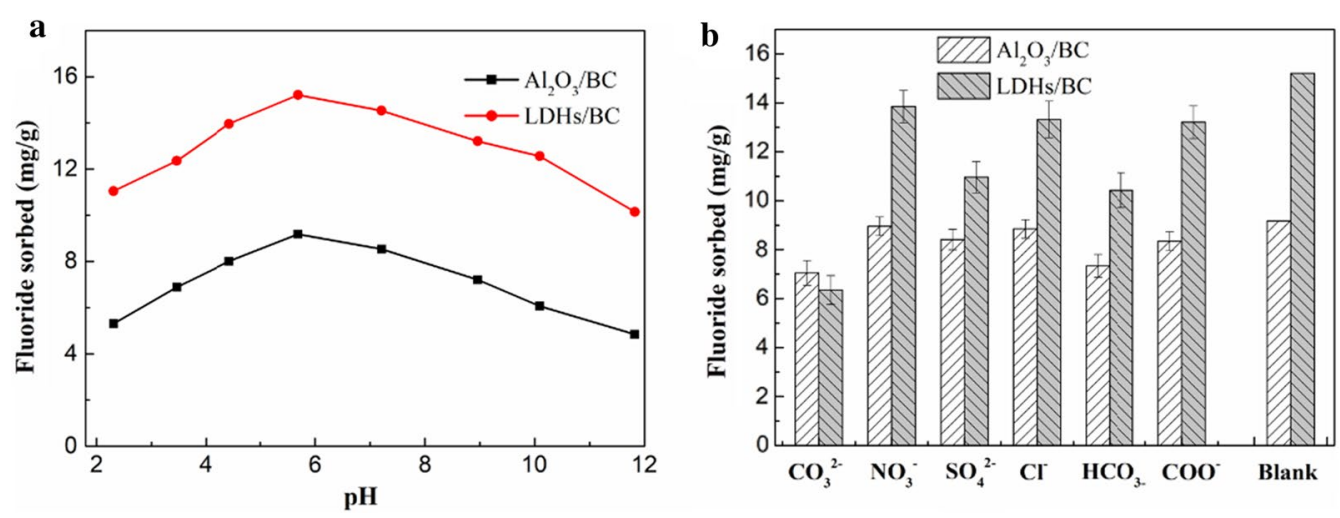

Fig. 2 Effect of solution pH (a) and coexisting ions (b) on fluoride adsorption (adsorption time, $24 \mathrm{~h}$; adsorption temperature, $30^{\circ} \mathrm{C}$ )

was obtained at $\mathrm{pH}$ 5.71. Similar result was observed in the literature of other LDH-based materials for fluoride adsorption [11]. In addition, it can be obviously seen that the $\mathrm{LDH} / \mathrm{BCF}$ have higher fluoride adsorption capacities than that of $\mathrm{Al}_{2} \mathrm{O}_{3} / \mathrm{BCF}$. The $\mathrm{LDH}$ on BCF surfaces can adsorb more fluoride ion due to its high anion exchange capacity.

The selective fluoride adsorption by $\mathrm{LDH} / \mathrm{BCF}$ is an important factor because the various kinds of anions existed in actual surface water and groundwater. In consideration of several co-existing anions existed with fluoride species at high levels in natural waters, it is significant to affect the adsorption capacity of LDH/BCF sample towards fluoride under the circumstance of the co-existing anions, in which the competitive adsorption of co-existing anions to the adsorption sites may affect the fluoride adsorption capacity. The effects of $\mathrm{CO}_{3}{ }^{2-}$, $\mathrm{NO}_{3}{ }^{-}, \mathrm{SO}_{4}{ }^{2-}, \mathrm{Cl}^{-}, \mathrm{HCO}_{3}{ }^{-}$and $\mathrm{COO}^{-}$on the fluoride adsorption of on the $\mathrm{LDH} / \mathrm{BCF}$ were fixed at fluoride concentration of $60 \mathrm{mg} / \mathrm{L}$ with equal ionic strength of the co-existing anions at neutral $\mathrm{pH}$ and the corresponding results were illustrated in Fig. 2b. Apparently, the presence of the high negative charge anions $\left(\mathrm{CO}_{3}{ }^{2-}\right.$, $\mathrm{SO}_{4}{ }^{2-}$ and $\mathrm{HCO}_{3}{ }^{-}$) had negligible influence on fluoride adsorption. However, the existence of monovalent anions $\left(\mathrm{NO}_{3}{ }^{-}, \mathrm{Cl}^{-}\right.$and $\left.\mathrm{COO}^{-}\right)$reduced slightly the fluoride adsorption capacity. The effect of high negative charge anions on fluoride adsorption can be explained as (1) by affecting the competition of the co-existing anions and fluoride ions for available adsorption sites; (2) by affecting the ion exchange, and the high negative charge anions can easily be incorporated into the interlayer galleries of LDH. In addition, it can be seen that the fluoride adsorption capacities of the LDH/BCF synthesized in this work are higher than that of $\mathrm{Al}_{2} \mathrm{O}_{3} / \mathrm{BCF}$ owing to the introduction of LDH nanosheets. The LDH/BCF synthesized in this work have more available adsorption sites and stronger electrostatic interactions with fluoride ions that bare BCF.

The adsorption capacities of fluoride ions on LDH/ BCF were investigated via equilibrium experiments via control the fluorine concentrations and adsorption temperatures. Figure 3 shows the fluoride adsorption isotherms together with the Langmuir model's fit. As it indicates, the adsorbed fluoride at equilibrium gradually increased with increasing equilibrium fluoride concentrations. Comparison of several reported defluorination materials (Table S1), the LDH/BCF exhibited excellent fluoride adsorption capacities. The maximum adsorption capacities of fluoride on $\mathrm{Al}_{2} \mathrm{O}_{3} / \mathrm{BCF}$ and $\mathrm{LDH} / \mathrm{BCF}$ were $9.18 \mathrm{mg} / \mathrm{g}$ and $15.21 \mathrm{mg} / \mathrm{g}$, respectively. However, the BET surface area of $\mathrm{LDH} / \mathrm{BCF}$ is lower than that of

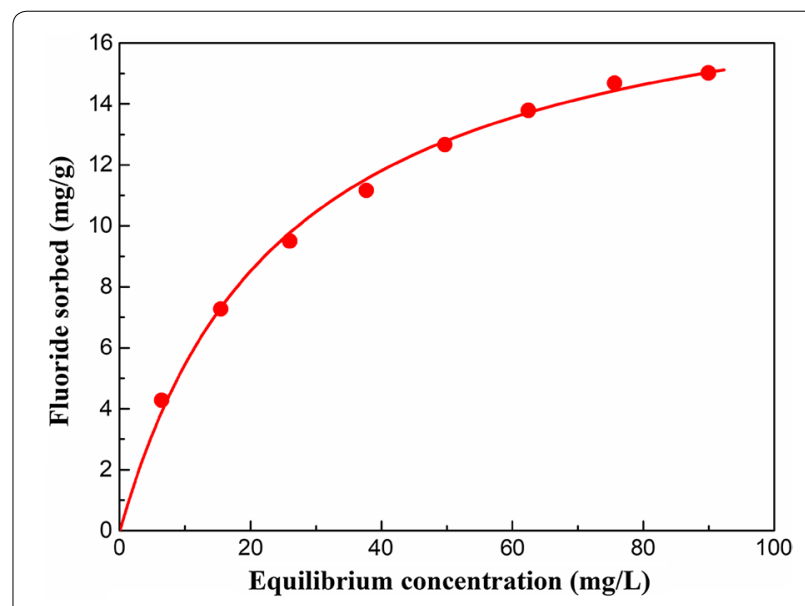

Fig. 3 Experimental equilibrium data (dots) and Langmuir fits (curves) fluoride adsorption onto LDH/BCF (adsorption time, $24 \mathrm{~h}$; adsorption temperature, $30^{\circ} \mathrm{C}$ ) 
$\mathrm{Al}_{2} \mathrm{O}_{3} / \mathrm{BCF}$, so the high affinity of $\mathrm{LDH} / \mathrm{BCF}$ towards fluoride was obvious.

Langmuir and Freundlich models [21] were applied to describe the fluoride adsorption process. By contrast, the experimental data of isotherm fitted well with the Langmuir isotherm model. The statistical values $R^{2}$ for Langmuir isotherm model $\left(R^{2}=0.99\right)$, suggesting that the fluoride adsorption could be well described by monolayer sorption model. Figure 3 shows the Langmuir fits for fluoride adsorption onto $\mathrm{LDH} / \mathrm{BCF}$ at different temperatures. The experimental data are very close to the Langmuir curve with the accurate calculation of $\mathrm{q}_{\max }$ $(17.56 \mathrm{mg} / \mathrm{g})$, implying that the surfaces active sites are homogeneously distributed on LDH/BCF.

The fluoride adsorption temperatures not only determine the adsorption isotherms, but also control the fluoride adsorption kinetics. The effect of adsorption temperature and adsorption time on fluoride adsorption was examined, and the results are shown in Fig. 4. Fluoride adsorption capacity gradually increased with the adsorption time, and the time required to reach the adsorption equilibrium of LDH/BCF was nearly $90 \mathrm{~min}$, which was similar to the equilibrium adsorption time of fluoride onto $\mathrm{CeO}_{2} / \mathrm{Al}_{2} \mathrm{O}_{3}$ composites as reported in our previous works [2]. The rapid kinetics are mainly attributed to the hierarchically porous of $\mathrm{LDH} / \mathrm{BCF}$, which

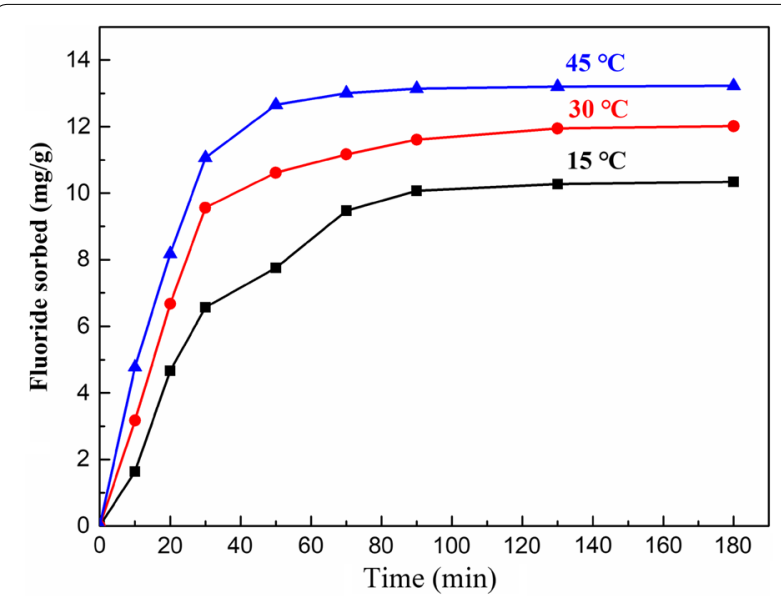

Fig. 4 Adsorption kinetics for fluoride adsorption onto LDH/BCF could favor for the accessibility of fluoride intercalation and diffusion into the interiors of materials. In addition, the adsorption kinetics reveal that fluoride adsorption capacity increased with the adsorption temperature, and the maximum fluoride adsorption capacity was increased from 10.34 to $13.23 \mathrm{mg} / \mathrm{g}$ with increasing of adsorption temperatures from 15 to $45^{\circ} \mathrm{C}$. The adsorption kinetics indicate the endothermic process of fluoride adsorption, which is in good agreement with the above adsorption isotherms. Such temperature dependence of favorable fluoride adsorption illustrates that the fluoride uptake onto $\mathrm{LDH} / \mathrm{BCF}$ is driven by surface reaction process spontaneously.

The above-mentioned fluoride adsorption processes were fitted by pseudo-first order equation, pseudo-second order equation and intraparticle diffusion kinetic models [22-24] and the results are displayed in Table 1. The fitting results indicated that the data were better fitted to the reaction model than to the diffusion models. The very accurate calculation of maximum fluoride adsorption properties as well as the relatively high correlation coefficient $\left(R^{2}\right)$ values indicate that fluoride adsorption onto LDH/BCF followed the pseudo-second order kinetic model. The characteristic adsorption curves are related to the surface interaction by analyzing pseudo-second order kinetic model. The fast fluoride adsorption rate and the high fluoride adsorption capacity indicated that $\mathrm{LDH} / \mathrm{BCF}$ was potential adsorbents for defluorination.

To investigate the surface properties changes after adsorption, XPS was used to investigate the compositions and chemical state of the elements on adsorbents, providing useful information on fluoride adsorption process. Figure 5 shows the XPS spectra of LDH/BCF absorbents before and after fluoride adsorption. As can been in wide-scan XPS spectra (Fig. 5a), the peak positions of aluminum, oxygen and carbon are consistent with the previous report, and the peaks of magnesium and fluorine are observed evidently. The $\mathrm{Mg} 2 \mathrm{p}$ and $\mathrm{Al} 2 \mathrm{p}$ spectra in Fig. $5 \mathrm{~b}$ indicates that the peak at $50.1 \mathrm{eV}$ and $75.1 \mathrm{eV}$ are typical of mixed metal oxide on the surfaces of BCF. Figure 5c displays the highresolution $C$ 1s spectra. It is indicated that higher binding energy shown at $283.17 \mathrm{eV}$, $284.78 \mathrm{eV}, 286.32 \mathrm{eV}$ and $289.11 \mathrm{eV}$ are assigned to

Table 1 Kinetic model parameters for adsorption of fluoride

\begin{tabular}{|c|c|c|c|c|c|c|}
\hline \multirow[t]{2}{*}{ Temperatures $\left({ }^{\circ} \mathrm{C}\right)$} & \multicolumn{2}{|c|}{ Pseudo-first-order } & \multicolumn{2}{|c|}{ Pseudo-second-order } & \multicolumn{2}{|c|}{ Intraparticle diffusion } \\
\hline & $\mathrm{K}_{1}\left(\min ^{-1}\right)$ & $\mathrm{R}^{2}$ & $\mathrm{~K}_{2}\left(\mathrm{~g} \mathrm{mg}^{-1} \mathrm{~min}^{-1}\right)$ & $\mathrm{R}^{2}$ & $\mathrm{~K}_{\mathrm{l}}\left(\mathrm{mg} \mathrm{g}^{-1} \mathrm{~min}^{-1 / 2}\right)$ & $\mathrm{R}^{2}$ \\
\hline 15 & $4.028 \times 10^{-2}$ & 0.9849 & $3.224 \times 10^{-3}$ & 0.9897 & 0.8722 & 0.8720 \\
\hline 30 & $3.854 \times 10^{-2}$ & 0.9875 & $3.684 \times 10^{-3}$ & 0.9850 & 0.9375 & 0.7978 \\
\hline 45 & $5.092 \times 10^{-2}$ & 0.9742 & $5.685 \times 10^{-3}$ & 0.9923 & 0.9927 & 0.9474 \\
\hline
\end{tabular}



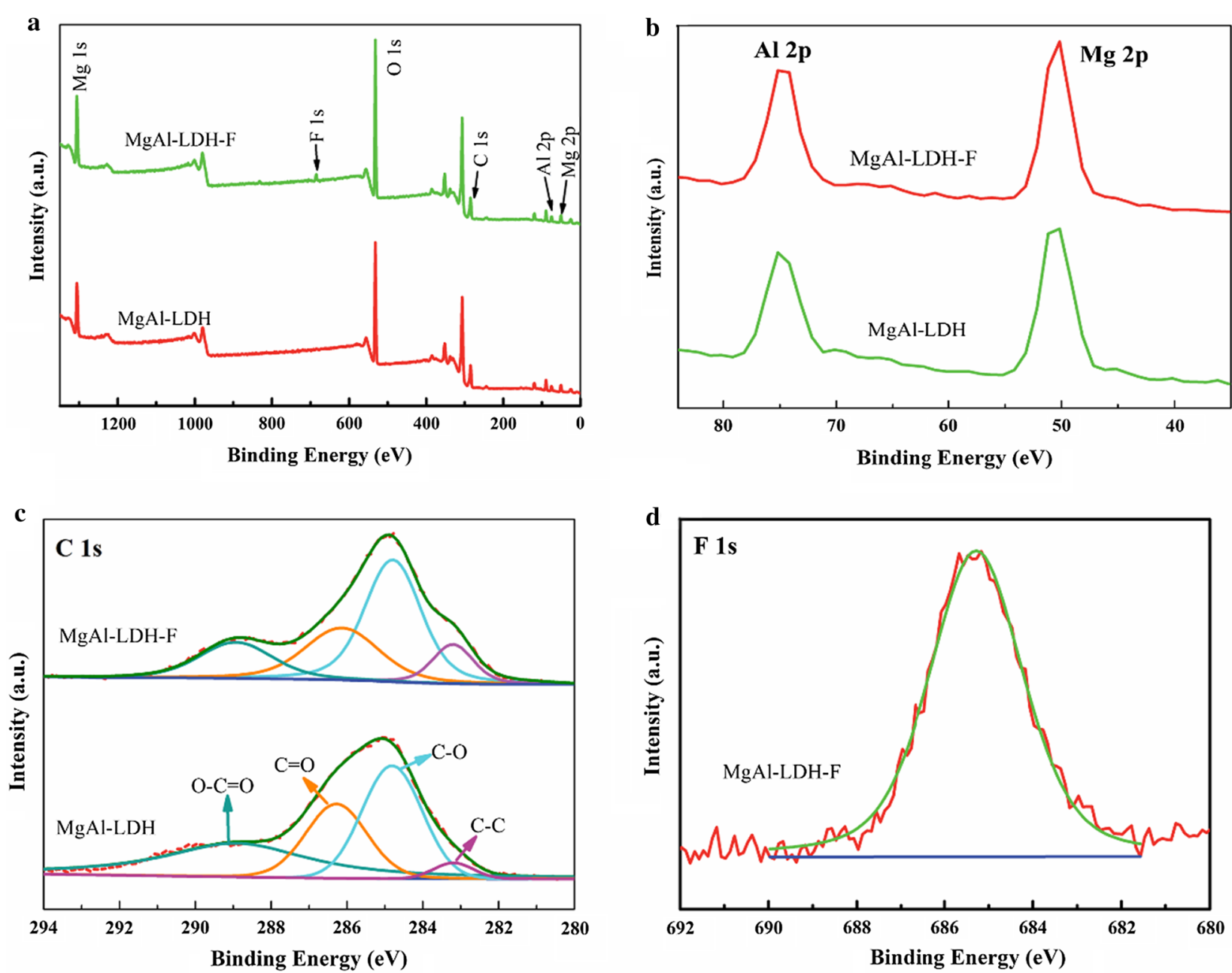

Fig. 5 a Survey XPS spectrum of MgAl-LDH and MgAl-LDH-F, high-resolution XPS spectra of $\mathbf{b}$ Al 2p and Mg 2p, c C 1s and $\mathbf{d} F$ is

biomass carbon of $\mathrm{LDH} / \mathrm{BCF}$ absorbents, indicating the existence of $\mathrm{C}-\mathrm{C}, \mathrm{C}-\mathrm{O}, \mathrm{C}=\mathrm{O}$ and $\mathrm{O}-\mathrm{C}=\mathrm{O}$ bonds, respectively. Additional file 1: Fig. S6 shows XPS spectra of $\mathrm{O} 1 \mathrm{~s}$ before and after fluoride adsorption. It can be seen in Additional file 1: Fig. S6 that the binding energy of $\mathrm{O} 1 \mathrm{~s}$ spectrum shifted towards the high energy side. In addition, slight changes are observed in the characteristic peak of $\mathrm{Al} 2 \mathrm{p}$. Hence, the adsorption reaction may be involved in fluoride ions and hydroxide group. Similar results were also obtained by FT-IR spectra (see Additional file 1: Fig. S3).

In conclusion, LDH/BCF was prepared by the combined sol-gel, carbonization and hydrothermal processes using sustainable bamboo fibers as raw material. Morphological and structural characterizations were performed using SEM, XRD and BET analyses. The results confirmed that the surfaces of the $\mathrm{BCF}$ are covered by a layer of LDH nanosheets, forming the hierarchical porous structures. The BET surface areas of $\mathrm{Al}_{2} \mathrm{O}_{3} / \mathrm{BCF}$ and $\mathrm{LDH} / \mathrm{BCF}$ are 59.61 and $39.89 \mathrm{~m}^{2} / \mathrm{g}$, respectively. The LDH/BCF have higher fluoride adsorption capacity than that of $\mathrm{Al}_{2} \mathrm{O}_{3} / \mathrm{BCF}$ due to its high anion exchange capacities. The solution $\mathrm{pH}$ of the solution is crucial for fluoride adsorption and the optimum $\mathrm{pH}$ for fluoride adsorption appeared at $\mathrm{pH}$ 3.5-9.0. The relatively high correlation coefficient values from the experimental and fitting values of the isotherm and kinetics demonstrated that fluoride adsorption processes onto the LDH/BCF adsorbent were well fitted using the Langmuir isotherms model and pseudo-second order model. Interestingly, the LDH/BCF maintained stable and high adsorption capacity for fluoride over 5 consecutive cycles. Therefore, the $\mathrm{LDH} / \mathrm{BCF}$ was found to be a promising adsorbent for removing fluoride from fluoride contaminated water. 


\section{Additional file}

Additional file 1. Supplementary material.

\section{Authors' contributions}

DY and TZ conceived the concept and designed the experiments. TZ, DY and BZ synthesized materials and performed adsorption experiment. QC and XP conducted materials characterization. TZ, QC and FQ co-wrote the manuscript. All authors read and approved the final manuscript.

\section{Author details}

${ }^{1}$ Institute of Green Chemistry and Chemical Technology, School of Chemistry and Chemical Engineering, Jiangsu University, Zhenjiang 212013, China. ${ }^{2}$ School of Civil Engineering and Architecture, East China Jiaotong University, Jiangxi 330013, China.

\section{Acknowledgements}

This work was financially supported by National Nature Science Foundation of China (21706100, 21878132 and U1507115), Natural Science Foundation of Jiangsu Province (BK20160500, BK20161362 and BK20160491), the China Postdoctoral Science Foundation (2016M600373, 2018T110452 and 2017M621649), China Postdoctoral Science Foundation of Jiangsu Province (1601016A, 1701067C and 1701073C), Scientific Research Foundation for Advanced Talents, Jiangsu University (15JDG 142), High-Level Personnel Training Project of Jiangsu Province (BRA2016142) and Key Research and Development Program of Jiangxi Province (20171BBH80008)

\section{Competing interests}

The authors declare that they have no competing interests.

\section{Publisher's Note}

Springer Nature remains neutral with regard to jurisdictional claims in published maps and institutional affiliations.

Received: 4 October 2018 Accepted: 30 November 2018

Published online: 06 March 2019

\section{References}

1. Biswas K, Gupta K, Ghosh UC (2009) Adsorption of fluoride by hydrous iron(III)-tin(IV) bimetal mixed oxide from the aqueous solutions. Chem Eng J 149:196-206

2. Zhang T, Li Q, Liu Y, Duan Y, Zhang W (2011) Equilibrium and kinetics studies of fluoride ions adsorption on $\mathrm{CeO}_{2} / \mathrm{Al}_{2} \mathrm{O}_{3}$ composites pretreated with non-thermal plasma. Chem Eng J 168:665-671

3. Mourabet M, El Rhilassi A, El Boujaady H, Bennani-Ziatni M, Taitai A (2017) Use of response surface methodology for optimization of fluoride adsorption in an aqueous solution by Brushite, Arabian. J Chem 10:S3292-S3302

4. $\quad$ Pi K, Wang Y, Xie X, Su C, Ma T, Li J, Liu Y (2015) Hydrogeochemistry of co-occurring geogenic arsenic, fluoride and iodine in groundwater at Datong Basin, northern China. J Hazard Mater 300:652-661

5. Iriel A, Bruneel SP, Schenone N, Cirelli AF (2018) The removal of fluoride from aqueous solution by a lateritic soil adsorption: kinetic and equilibrium studies. Ecotoxicol Environ Saf 149:166-172

6. Hu CY, Lo SL, Kuan WH (2003) Effects of co-existing anions on fluoride removal in electrocoagulation (EC) process using aluminum electrodes. Water Res 37:4513-4523
7. Harrison PTC (2005) Fluoride in water: a UK perspective. J Fluor Chem 126:1448-1456

8. Bhatnagar A, Kumar E, Sillanpää M (2011) Fluoride removal from water by adsorption-a review. Chem Eng J 171:811-840

9. Yu Z, Xu C, Yuan K, Gan X, Feng C, Wang X, Zhu L, Zhang G, Xu D (2018) Characterization and adsorption mechanism of $\mathrm{ZrO}_{2}$ mesoporous fibers for health-hazardous fluoride removal. J Hazard Mater 346:82-92

10. Swain SK, Mishra S, Patnaik T, Patel RK, Jha U, Dey RK (2012) Fluoride removal performance of a new hybrid sorbent of $\mathrm{Zr}(\mathrm{IV})$-ethylenediamine. Chem Eng J 184:72-81

11. Zhang T, Yu H, Zhou Y, Rong J, Mei Z, Qiu F (2016) Enhanced adsorption of fluoride from aqueous solutions by hierarchically structured Mg-Al LDHs/ $\mathrm{Al}_{2} \mathrm{O}_{3}$ composites, Korean. J Chem Eng 33:720-725

12. Huang H, Liu J, Zhang P, Zhang D, Gao F (2017) Investigation on the simultaneous removal of fluoride, ammonia nitrogen and phosphate from semiconductor wastewater using chemical precipitation. Chem Eng J 307:696-706

13. Djouadi Belkada F, Kitous O, Drouiche N, Aoudj S, Bouchelaghem O, Abdi N, Grib H, Mameri N (2018) Electrodialysis for fluoride and nitrate removal from synthesized photovoltaic industry wastewater. Sep Purif Technol 204:108-115

14. Li Y, Huang S, Zhou S, Fane AG, Zhang Y, Zhao S (2018) Enhancing water permeability and fouling resistance of polyvinylidene fluoride membranes with carboxylated nanodiamonds. J Membr Sci 556:154-163

15. Yuan D, Zhang T, Guo Q, Qiu F, Yang D, Ou Z (2018) Recyclable biomass carbon@SiO $@ \mathrm{MnO}_{2}$ aerogel with hierarchical architectures for fast and selective oil-water separation. Chem Eng J 351:622-630

16. Li F, Li D, Li X, Liao J, Li S, Yang J, Yang Y, Tang J, Liu N (2016) Microorganism-derived carbon microspheres for uranium removal from aqueous solution. Chem Eng J 284:630-639

17. Yue X, Li J, Zhang T, Qiu F, Yang D, Xue M (2017) In situ one-step fabrication of durable superhydrophobic-superoleophilic cellulose/LDH membrane with hierarchical structure for efficiency oil/water separation. Chem Eng J 328:117-123

18. Yue X, Zhang T, Yang D, Qiu F, Li Z, Zhu Y, Yu H (2018) Oil removal from oily water by a low-cost and durable flexible membrane made of layered double hydroxide nanosheet on cellulose support. J Clean Prod 80:307-315

19. Zhang T, Zhou Y, Bu X, Xue J, Hu J, Wang Y, Zhang M (2014) Bio-inspired fabrication of hierarchically porous $\mathrm{Mg}-\mathrm{Al}$ composites for enhanced BSA adsorption properties. Microporous Mesoporous Mater 188:37-45

20. Zhang T, Zhou Y, Wang Y, Bu X, Wang H, Zhang M (2015) Morphologycontrolled fabrication of hierarchical $\mathrm{LDH} / \mathrm{C}$ microspheres derived from rape pollen grain. Appl Clay Sci 103:67-70

21. Yu H, Chu Y, Zhang T, Yu L, Yang D, Qiu F, Yuan D (2018) Recovery of tellurium from aqueous solutions by adsorption with magnetic nanoscale zero-valent iron (NZVFe). Hydrometallurgy 177:1-8

22. Ho Y-S (2006) Second-order kinetic model for the sorption of cadmium onto tree fern: a comparison of linear and non-linear methods. Water Res 40:119-125

23. Ho YS, McKay G (2000) The kinetics of sorption of divalent metal ions onto sphagnum moss peat. Water Res 34:735-742

24. Chen PH, Hsu C-F, Tsai DD-W, Lu Y-M, Huang W-J (2014) Adsorption of mercury from water by modified multi-walled carbon nanotubes: adsorption behaviour and interference resistance by coexisting anions. Environ Technol 35:1935-1944 